\title{
Pathways to Prevention: Improving Nonresident African American Fathers' Parenting Skills and Behaviors to Reduce Sons' Aggression
}

\author{
Cleopatra Howard Caldwell \\ School of Public Health, University of Michigan
}

\author{
Cathy L. Antonakos \\ Program for Research on Black Americans, \\ Research Center for Group Dynamics, \\ University of Michigan
}

\author{
E. Hill De Loney \\ Flint Odyssey House
}

\author{
Shervin Assari and Daniel Kruger \\ School of Public Health, University of Michigan
}

\author{
Rashid Njai \\ School of Public Health, University of Michigan
}

\begin{abstract}
This study describes a test of the Fathers and Sons Program for increasing intentions to avoid violence and reducing aggressive behaviors in 8- to 12-year-old African American boys by enhancing the parenting skills satisfaction and parenting behaviors of their nonresident fathers. The study included 158 intervention and 129 comparison group families. Structural equation model results indicated that the intervention was effective for improving fathers' parenting skills satisfaction, which was positively associated with sons' satisfaction with paternal engagement. Sons' paternal engagement satisfaction was positively associated with their intentions to avoid violence. Although aggressive behaviors were lower for comparison group sons, the intervention effectively reduced sons' aggressive behaviors indirectly by enhancing fathers' parenting behaviors. Support for family-centered youth violence prevention efforts is discussed.
\end{abstract}

Previous research has found that protective parenting behaviors, especially maintaining good parentchild relationships and effectively communicating values and expectations about risky behaviors, are necessary for positive youth outcomes (Blake, Simkin, Ledsky, Perkins, \& Calabrese, 2001; Brody et al., 2004; Murry, Berkel, Brody, Miller, \& Chen, 2009). Prosocial parental socialization regarding risky behaviors during late childhood and preadolescence is primarily important because most youth have not begun to question their own values or beliefs about risky behaviors and peer norms are not yet prominent. Therefore, parental values and expectations will have significant influence on their children's belief systems and behaviors (Farrell,

This research was funded by the Centers for Disease Control and Prevention through Grant R06/CCR521580 to the first author. Partial support also was provided through the Community Foundation of Flint, MI. The authors would like to thank members of the Project's Steering Committee for their insightful and dedicated work on this project, and the many fathers and sons who participated in the study.

Correspondence concerning this article should be addressed to Cleopatra Howard Caldwell, School of Public Health, University of Michigan, 1415 Washington Heights, Ann Arbor, MI 481092029. Electronic mail may be sent to cleoc@umich.edu.
Henry, Mays, \& Schoeny, 2011; Thornton, Craft, Dahlberg, Lynch, \& Baer, 2002). Thus, enhancing parenting behaviors in family-centered youth preventive interventions prior to and during adolescence is a critical strategy for protecting youth from harm because developmental changes and transitions occur during these life stages for both parents and adolescents.

The purpose of this study was to test the effectiveness of the Fathers and Sons Program for enhancing the parenting skills satisfaction and parenting behaviors of nonresident African American fathers as strategies for increasing intentions to avoid violence and reduce aggressive behaviors in their 8- to 12-year-old sons. Building upon the protective parenting behaviors literature and guided by a theoretical framework that considers subjective norms and culture, this study assesses a family strengths approach in preventing youth violence.

(C) 2013 The Authors

Child Development (c) 2013 Society for Research in Child Development, Inc. All rights reserved. 0009-3920/2014/8501-0021

DOI: $10.1111 /$ cdev.12127 
Parenting Behaviors and Youth Violence Among African Americans

Although adolescent development is influenced by multiple social contexts in which adolescents are embedded, including families, peer groups, school environments, neighborhoods, and cultural and political systems (Bronfenbrenner, 1977; Spencer, 2006), parents remain the primary socializing agent responsible for teaching children how to respond in social situations and different environments. Dahlberg and Potter (2001) highlight the complex interplay between biological processes, social factors, and external environmental conditions that can impede prosocial or competencepromoting parenting practices that are critical to protect children from chronic stressors and exposures to risk factors for youth violence. They note that rejection and neglect from parents contribute to the likelihood of aggressive behaviors in children, with negative family environments placing them on a developmental trajectory for severe violence.

Numerous studies support the significance of effective parent-child communication (Blake et al., 2001; Dilorio, McCarty, \& Denzmore, 2006), parental monitoring (Li, Feligelman, \& Stanton, 2000; Murphy, Marelich, Herbeck, \& Payne, 2009, parental involvement (Coley \& Medeiros, 2007), parentchild connectedness, and supportive parenting (Kim \& Brody, 2005; Wills, Gibbons, Gerrard, Murry, \& Brody, 2003) as vital for successful child outcomes. Thus, a functional family environment is necessary for successful social development in children and adolescents with implications for violence prevention (see Dahlberg \& Potter, 2001, for a review).

Studies of parenting and youth violence consistently show that parenting behaviors are affected by cultural and socioeconomic variations in the family environment, are informed by racial experiences, and occur within the broader society (Copeland-Linder, Lambert, Chen, \& Ialongo, 2011; Griffin, Botvin, Scheier, Diaz, \& Miller, 2000). These dynamics present additional challenges for African American families with adolescents who remain disproportionately represented in impoverished communities (U.S. Department of Health \& Human Services, 2001). Adolescence is a time of many social, emotional, and physiological changes, and when these changes are coupled with environmental exposures such as violent neighborhoods, poverty, inadequate school climates, and stressful family environments, African American adolescents are placed at risk for less than optimum outcomes (Murry et al., 2009; Spencer, 2006), including violence victimization and perpetration. Gutman, McLoyd, and Tokoyama (2005) and McLoyd (1998) effectively demonstrated the significance of economic stress on African American family functioning and identified mechanisms through which poverty disrupts supportive parenting to adversely affect the social development of adolescents. Neighborhood stress was a key mediator in this process. Thus, where families live is important to consider.

Longitudinal research indicates that caring and supportive family environments can disrupt the developmental course of violence from less severe aggressive behaviors to more severe violent acts as children age (Kim \& Brody, 2005; Roberts et al., 2012). In a 5-year longitudinal study of maternal functioning and psychological adjustment in rural African American families, Kim and Brody (2005) found that more maternal support, involvement, and monitoring, and less arguing when children were 11 years old were associated with their later self-regulation behaviors. Self-regulation was then related to less externalizing behavior 4 years later as children reached midadolescence. They concluded that competence-promoting parenting was critical to successful youth outcomes.

Research through a cultural lens emphasizes the importance of race-related socialization as an additional parenting practice used by African Americans to protect children from discriminatory experiences they are likely to encounter because of their race (Hughes et al., 2006). In a national study of ethnically diverse Black youth, Seaton, Caldwell, Sellers, and Jackson (2008) found that $80 \%$ of 13- to 17-year-old adolescents reported experiencing at least one discriminatory episode in the previous year. Others have found from $50 \%$ to $94 \%$ of African American youth reported experiencing racial discrimination (Fisher, Wallace, \& Fenton, 2000; Harris-Britt, Valrie, Kurtz-Costes, \& Rowley, 2007; Roberts et al., 2012). Garcia Coll et al. (1996) describe discriminatory experiences as normative for youth of color because of the pervasiveness of racism in American society resulting in a system of social stratification based on race, ethnicity, gender, and class. Managing race-related stress is often a focus in youth violence research involving African Americans because of the association between racial discrimination and violent behaviors among African American youth found in past research, especially for male youth (Copeland-Linder et al., 2011). 


\section{Parenting Behaviors Among Nonresident African American Fathers}

A growing body of research indicates that father involvement is important to the well-being of their children (Carlson, 2006; Griffin et al., 2000; King \& Sobolewski, 2006; Mackey \& Immerman, 2004; Marsiglio, Amato, Day, \& Lamb, 2000). This research typically focuses on White, middle-class, resident fathers of infants and young children, with less attention to African American fathers. Even less attempt has been made to understand the role of nonresident African American fathers in the lives of their children and how they parent their sons and daughters given the social and economic challenges many face (King, Harris, \& Heard, 2004; Leavell, Tamis-LeMonda, Ruble, Zosuls, \& Cabrera, 2012).

A notable demographic shift in the past 30 years is that approximately one third of all U.S. births are nonmarital, with more than two thirds of African American children born to unmarried mothers (National Fatherhood Initiative, 2011; U.S. National Center for Health Statistics, 2010). This means that a substantial number of children will live apart from their biological father, all or part of their childhood. Edin, Tach, and Mincy (2009) analyzed data from the Fragile Family and Child Well-Being Study, one of the largest studies of nonresident fathers to date. They found that nonresident fathers were more involved with their children than previously indicated in past research. They also found that African American fathers were less likely than White fathers to live with their children at birth, but they were more likely to remain involved after romantic relationships with mothers ended. Other researchers have found that the proportion of uninvolved nonresident fathers of school-age children has diminished over the past 25 years (Amato, Meyers, \& Emery, 2009; King \& Sobolewski, 2006). Consequently, the parenting behaviors of involved nonresident fathers represent an additional family influence to understand beyond maternal behaviors when examining child outcomes.

Available research on nonresident parenting by African American fathers documents ways in which their involvement can be beneficial to their children. Based on national data, King et al. (2004) found that nonresident African American and Hispanic fathers assisted their adolescent children with school projects more often than nonresident White fathers, and that African American fathers engaged in religious activities with their adolescent children at higher rates than other fathers. These activities were identified as promoting adolescent well-being and demonstrating unique contributions nonresident fathers can make even though they were not living with their children. Bryant and Zimmerman (2003) noted that nonresident African American fathers were more likely to live closer to their children than fathers of other races and they visited their children more frequently, whereas King et al. (2004) found that African American adolescents reported being closer to their nonresident father than White youth. Some nonresident fathers appear to be especially vigilant when youth were in trouble. For example, in a longitudinal study of nonresident father involvement and adolescent delinquency, Coley and Medeiros (2007) found that, compared to other fathers, nonresident African American fathers increased their involvement when their adolescent children became involved with nonviolent delinquency. Collectively, these findings suggest that some nonresident African American fathers remain actively involved with their children and can be positive supports.

Unique aspects of African American family life that favor nonresident father involvement included flexibility in family boundaries and the more egalitarian nature of parental relationships (Hunter \& Sellers, 1998). However, relationship conflict, child support issues, and multiple partner fertility can be barriers to father involvement (Amato et al., 2009; Edin et al., 2009). Coparenting with children's mother was one of the best predictors of father involvement, and better quality of relationship with mother was associated with more father involvement (Isacco, Garfield, \& Rogers, 2010). Despite barriers, nonresident African American fathers remained more involved with their children than other nonresident fathers (Coley \& Medeiros, 2007; Edin et al., 2009; King et al., 2004). Therefore, they represent a critical component of the family system to consider for participation in family-centered youth violence prevention efforts.

Rosenberg, Lyndee, and Knox (2005) noted that 30 years of violence prevention research has yielded important lessons for youth violence prevention programs, including "beginning young, using a social ecological approach, developing youth competencies, and incorporating risk reduction and protection strategies" (p. 185). Incorporating these strategies into prevention programs will result in a consistent foundation of knowledge for preventing youth violence. This study contributes to this knowledge by expanding family protection strategies to include nonresident fathers as part of the family environment in social ecological approaches. 
Youth Violence Intervention Research With High-Risk and African American Families

More studies now examine the link between protective parenting behaviors in family-centered interventions for youth at risk for violence and with African American families. The Multisite Violence Prevention Project (MVPP, 2009; Smith et al., 2004) and The Strong African American Families Program (SAAF; Brody et al., 2004) are two exemplary programs.

The MVPP is unique in that it is a comprehensive multisite collaboration funded by the Centers for Disease Control and Prevention (CDC) to reduce youth violent and aggressive behaviors involving schools and families (Smith et al., 2004). Over 600 families (child and primary caretaker) with high-risk or socially influential youth participated in the family-based intervention component. Approximately 5,600 students (48\% African American) participated in the school-based component. Results of the combined universal intervention with schools and the selective intervention with families showed less physical aggression at the school level where the family interventions were held over time. That is, effects were not found at the end of the intervention; however, effects emerged over the 2-year follow-up period (MVPP, 2009). A subsequent study found a link between parental monitoring and less aggressive behavior for males and females. It also revealed protective effects for parental involvement and messages regarding fighting and nonviolence as moderators of school norms for aggression and peer influences on aggression among females. However, these results diminished over time (Farrell et al., 2011). The authors concluded that parental attitudes may be most protective for physical aggression at the beginning of sixth grade.

The second intervention is SAAF. Working with rural African American mothers and their 11-yearold children, Brody et al. (2004) conducted a family-centered intervention to prevent multiple youth problem behaviors. In a study of youth violence, they reported the significance of the cumulative effects of parent involvement, communicating about sex, risky behaviors, and race-related socialization. This research highlighted the relevance of parenting behaviors generally and specifically related to cultural parenting for promoting positive outcomes among African American youth. Both the MVPP and SAAF demonstrated the value of involving parents in interventions for reducing aggressive behaviors during preadolescence.

\section{The Current Study}

The purpose of this study was to test the effectiveness of the Fathers and Sons Program for enhancing parenting skills satisfaction and parenting behaviors focused on risk communication for nonresident African American fathers, linking these outcomes to their 8- to 12-year-old sons' intentions to avoid violence and aggressive behaviors. This study tested components of a larger conceptual model that guided this theoretically based, culturally oriented, gender-specific, family-centered intervention. (See Caldwell et al., 2004, for a description of the full model.) As with other social ecological approaches, we envision the child embedded within the family, and the family embedded within a community with high violence exposure. The Fathers and Sons Program was designed to strengthen nonresident father-sons relationships while preventing youth risky behaviors.

\section{Theoretical Framework}

The theory of reasoned action (TRA; Ajzen \& Fishbein, 1980) was at the center of the conceptual model that guides the Fathers and Sons Program because of the intentionality and future orientation in its conceptualization. Specifically, TRA suggests that the most important determinant of future behaviors is what the person plans or intends to do in the future (i.e., his or her behavioral intentions). These intentions are composed of what the person thinks about violence and what he or she believes people important to him or her (e.g., fathers) think about violence (i.e., subjective norms). We focused on sons' intentions to avoid violence and their less severe aggressive behaviors as developmental precursors to youth violence. TRA assumes that a person will process information from important people and will act based on how much he or she is motivated to comply with what important people want him or her to do (subjective norm). Communication from fathers to sons as important people in their life and their motivation to comply reflect the subjective norm component of TRA. Fathers' satisfaction with their own risk communication parenting skills and sons' assessment of fathers' parenting engagement captures the communication of expectations and values from fathers to sons about violence and other risky behaviors as required by TRA.

We supplemented TRA with two models to account for broader interpersonal factors. We incorporated social support (Israel \& Rounds, 1987) to capture providing for sons' emotional and instrumental 
needs and the culturally relevant racial socialization (Hughes et al., 2006). Racial socialization posits that African American parents prepare their children to cope with racial discrimination as a protective strategy for dealing with racially hostile environments. As specified in the integrative model for children of color by Garcia Coll et al. (1996), when parents are successful they have taught their children strategies to maintain a strong sense of self when children are exposed to threats stemming from racism and discrimination. Fathers' communication about racial issues reflects not only their individual beliefs but also their history, traditions, and survival skills transmitted across generations. Thus, the imparting of race-related messages should result in adaptive competencies in their sons.

\section{Study Hypotheses}

On the basis of the above framework, we tested several hypotheses. We hypothesized that the Fathers and Sons Program would improve fathers' parenting skills satisfaction, which we defined as satisfaction with their ability to parent in specific areas and their overall parenting satisfaction. Specifically, improving fathers' satisfaction with their parenting skills would be associated with sons' satisfaction with how engaged fathers were in parenting, which in turn would be associated with sons' intentions to avoid violence in the future. We also hypothesized that the Fathers and Sons Program would enhance fathers' parenting behaviors focused on communicating with sons about risky behaviors, race-related socialization, and sex. Enriched parenting behaviors for risk communication would be associated with less aggression in sons. Thus, the intervention was expected to reduce sons' aggressive behaviors indirectly through its effects on fathers' parenting behaviors. Finally, because our ultimate goal was to prevent youth violence, we assessed the parenting behaviors model for its influence on sons' intentions to avoid future violence. We hypothesized that improving fathers' parenting behaviors would reduce aggressive behaviors in sons, which would then be associated with an increase in their intentions to avoid future violence.

\section{Method \\ Sample}

The sample consisted of 287 nonresident African American fathers and 287 sons, ages 8 to 12 years old. Three fathers who were not biological participated because they had been the son's father figure since birth. We used a quasi-experimental study design to evaluate the intervention's effectiveness with 158 father-son dyads in the intervention group and 129 father-son dyads in the comparison group (Caldwell, Rafferty, Reischl, De Loney, \& Brooks, 2010). The nonresident fathers in this study ranged in age from 22 to 63 years, with a mean age of 37.4 $(S D=7.7)$. About $13 \%$ of the fathers were married, whereas $16.7 \%$ were living with a partner, $16.4 \%$ were divorced, $9.4 \%$ were separated, $1.0 \%$ was widowed, and $43.2 \%$ were never married. Only $19.2 \%$ of the fathers were ever married to the mother of their sons in the study. The majority of fathers had a high school education or General Education Degree (GED) or more $(78.1 \%)$ and about half $(51 \%)$ were employed. Most fathers (55.7\%) reported that they barely had enough or did not have enough money to get by. However, $73.2 \%$ reported that they had a legal child support agreement for their sons. About $77 \%$ of the fathers had lived with their sons, whereas $23 \%$ had never lived with them. Among fathers who had lived with their sons, most reported living with them until they were 5 years old or younger $(63 \%)$.

The sons in the study were 8-12 years old, with an average age of $10.2(S D=1.4)$. Their average grade at the time of the study was fifth grade $(S D=1.4)$, and on average, they had 3.5 siblings $(S D=2.5)$. From the sons' perspective, $63.1 \%$ remembered living with their father.

Table 1 provides a description of the sample by intervention and comparison groups. The two groups were compared on baseline demographic characteristics using two-sample $t$ tests and chisquare tests of association. Results show that the two groups were fairly comparable with the following exceptions: Intervention group fathers lived with their sons longer before becoming nonresident, $\chi^{2}(2)=11.04, p=.004$; comparison group sons were older, $t(284)=2.581, p=.01$; and intervention group sons had more siblings, $\chi^{2}(1)=7.61, p=.006$. These variables were included as covariates in multivariate analyses to account for initial group differences.

\section{Procedure}

The Fathers and Sons Project was funded by the CDC to develop and evaluate a theory-based, culturally relevant, family-centered intervention program designed to prevent youth risky health behaviors by strengthening relationships between nonresident African American fathers and their 8- to 12-year-old biological sons. The program is 
Table 1

Demographic Characteristics of Fathers and Sons by Group at Baseline

Intervention Comparison

$(n=158) \quad(n=129)$

\begin{tabular}{lll}
\hline Fathers & & \\
Age in years, $M(S D)$ & $37.4(7.2)$ & $37.5(8.3)$ \\
Currently married, \% & 25.8 & 35.7 \\
Ever married to son's mother, \% & 17.7 & 21.1 \\
Less than high school education, \% & 22.3 & 21.6 \\
Employed, \% & 51.9 & 49.6 \\
$\quad$ Perceived economic status, \% & 52.5 & 59.4 \\
$\quad$ Child support agreement, \% & 70.3 & 75.4 \\
How long lived with son & & \\
$\quad$ Never lived with son, \% & 22.5 & 27.9 \\
Lived with son 5 years or less, \% & 40.3 & 52.5 \\
$\quad$ Lived with son > 5 years, \% & 37.2 & $19.6^{* *}$ \\
Sons & & \\
$\quad$ Age in years, $M(S D)$ & $10.0(1.4)$ & $10.4(1.4)^{* *}$ \\
$\quad$ Grade level, $M(S D)$ & $4.7(1.4)$ & $5.0(1.3)$ \\
Number of siblings, \% & & \\
0-3 & 49.4 & 65.6 \\
4 or more & 50.6 & $34.4^{* *}$ \\
\hline
\end{tabular}

${ }^{* *} p<.01$.

unique in its focus on nonresident African American fathers' parenting skills and behaviors and promotes cultural awareness as critical strategies for protecting boys from specific risky health behaviors (i.e., violent behavior, substance use, and early sexual initiation). It was developed using a community-based participatory research approach (Israel, Eng, Schulz, \& Parker, 2005) that involved several community-based organizations, the local health department, and a university-based Prevention Research Center.

Families were recruited from two Midwestern cities 30 miles apart with similar demographic characteristics and high violence profiles, with one city being the location for the intervention program. Both were small urban cities with majority African American populations. About 69\% of the adults in both cities had a high school education or more, 31\% had incomes below the poverty level, and about $40 \%$ of households in each city were headed by females with children under 18 years of age and no husband present. The unemployment rate in the intervention city was $7 \%$ at the time of the study and it was $5 \%$ in the city where most comparison group families lived (Caldwell et al., 2010).

Most families were recruited from schools, with mothers or legal guardians being the first family contacted by school personnel. Mothers then recruited fathers. We recruited 185 families who met study criteria for the intervention, of which 162 families completed the program and the evaluation questionnaires. We did not use the data from four families because they were incomplete or the son was found to be ineligible due to his age at the time of the program. Therefore, we had a final intervention sample size of 158 father-son families. The response rate for the intervention group was $85.4 \%$. We identified 186 eligible families for the comparison group, 165 father-son families completed the pretest questionnaire, and 129 father-son families completed the posttest questionnaire for a response rate of $69.4 \%$. The overall response rate for the study was $77.4 \%$. Multiple sons from the same families participated in the intervention $(17 \%)$ or the comparison $(15 \%)$ group because they met study criteria. The results reported in this study are based on data from fathers and their eldest sons because there were too few second sons in the intervention $(n=27)$ and comparison $(n=19)$ groups to include in the analyses.

The intervention consisted of 15 sessions of about $2 \mathrm{hr}$ each. The details of the intervention are presented elsewhere (Caldwell et al., 2011). In sum, activities were designed to enhance knowledge, influence father-son relationships, and practice skills in specific content areas (e.g., culture and history, parent-child communication, parental monitoring, role modeling for fathers, race-related socialization, social support behaviors, cultural connections, preventing or reducing substance use, violent behaviors, and sexual debut among sons). The curriculum also included nine homework assignments to reinforce intervention content, $4 \mathrm{hr}$ of community cultural or service activities, in addition to evaluation data collection for a total of $45 \mathrm{hr}$ over approximately 2 months.

The average attendance for the 15 intervention sessions was $12.22(S D=3.13)$ for fathers and 12.50 $(S D=3.07)$ for sons. Moreover, $77.2 \%$ of fathers and $79.6 \%$ of sons attended 11 or more of the 15 sessions. Halfway through the intervention program and at the end of the program, fathers and sons received a financial incentive for their participation. Comparison group families completed preand posttest questionnaires in 2-month time frames like intervention families; however, no intervention activities were provided. Fathers were paid \$30 and sons were paid $\$ 15$ for each session attended. Both groups were paid to complete the study questionnaires. 


\section{Attrition Analysis}

We conducted an attrition analysis to determine whether characteristics of fathers and sons who completed posttest interviews $(n=287$ families $)$ were similar when compared to the $17 \%$ of families who did not complete the posttest ( $n=60$ families). Results revealed that fathers with a high school education were less likely to complete the posttest than those with more than a high school education, $\mathrm{OR}=0.40,95 \%$ CI $[0.17,0.95], p<.05$. Fathers who lived with their sons longer before becoming nonresident also were more likely to complete the posttest than those with less time together, $\mathrm{OR}=1.39$, $95 \%$ CI [1.01, 1.82], $p<.05$. Sons who lived with their fathers at some point were more likely to complete the posttest than those who had not, $\mathrm{OR}=2.03,95 \% \mathrm{CI}[1.01,4.06], p<.05$, and sons who reported better communication with their fathers were less likely to complete the posttest than those with worst communication, $\mathrm{OR}=0.89$, $95 \%$ CI $[0.78,1.00], p<.05$.

\section{Measures}

Parenting Skills Satisfaction and Sons' Intentions to Avoid Violence Measures

We used three scales to measure parenting skills satisfaction, which was operationalized as fathers' reports of their perceived ease in communicating with their son, their satisfaction with their involvement in multiple socialization tasks, and their overall satisfaction with their skills as a parent. Sons completed the perceived Parent-Child Communication and Parental Involvement Scales, reflecting their assessment of their father's engagement in these areas. Table 2 provides the components of each parenting skills satisfaction scale, along with the intentions to avoid violence measure. The means and standard deviations for the total sample, as well as the pre- and posttest Cronbach's alphas and means and standard deviations for each measure for fathers and sons by intervention and comparison groups are provided in Table 2. Each measure in the parenting skills model is described in more detail elsewhere for the total sample.

Perceived parent-child communication. Barnes and Olson's Parent-Child Communication Scale (Barnes \& Olson, 1985) assesses the perceived ease or difficulty of communication between parent and child. Fathers and sons were asked eight questions about their perceived ability to communicate with each other. An example question for fathers is as follows: "I think my son finds it easy to discuss problems with me." An example question for sons is as follows: "I can share how I feel about anything with my father." A 4-point response scale was used ranging from 1 (strongly disagree) to 4 (strongly agree). Items were summed to construct a scale with scores ranging from 8 to 32. Higher scores indicate more ease in communication between fathers and sons. Cronbach's alphas for fathers were as follows: pretest $=.61$ and posttest $=.70$; and sons: pretest $=.66$ and posttest $=.68$.

\begin{tabular}{|c|c|c|c|c|c|c|c|c|c|c|c|}
\hline & & \multicolumn{2}{|c|}{ Total sample } & \multicolumn{4}{|c|}{ Intervention group } & \multicolumn{4}{|c|}{ Comparison group } \\
\hline & & $\begin{array}{l}\text { Pretest } \\
M(S D)\end{array}$ & $\begin{array}{l}\text { Posttest } \\
M(S D)\end{array}$ & $\begin{array}{l}\text { Pretest } \\
\text { alpha }\end{array}$ & $\begin{array}{l}\text { Posttest } \\
\text { alpha }\end{array}$ & $\begin{array}{l}\text { Pretest } \\
M(S D)\end{array}$ & $\begin{array}{l}\text { Posttest } \\
M(S D)\end{array}$ & $\begin{array}{c}\text { Pretest } \\
\text { alpha }\end{array}$ & $\begin{array}{l}\text { Posttest } \\
\text { alpha }\end{array}$ & $\begin{array}{l}\text { Pretest } \\
M(S D)\end{array}$ & $\begin{array}{l}\text { Posttest } \\
M(S D)\end{array}$ \\
\hline \multirow[t]{3}{*}{$\begin{array}{l}\text { Fathers' parenting } \\
\text { skills satisfaction }\end{array}$} & $\begin{array}{l}\text { General parenting } \\
\text { skills }\end{array}$ & $\begin{array}{c}6.3 \\
(1.6)\end{array}$ & $\begin{array}{c}6.7 \\
(1.3)\end{array}$ & .76 & .58 & $\begin{array}{c}6.4 \\
(1.4)\end{array}$ & $\begin{array}{c}6.9 \\
(1.0)\end{array}$ & .79 & .90 & $\begin{array}{c}6.3 \\
(1.6)\end{array}$ & $\begin{array}{l}6.4 \\
(1.6)\end{array}$ \\
\hline & $\begin{array}{l}\text { Parenting } \\
\text { involvement }\end{array}$ & $\begin{array}{l}24.3 \\
(3.9)\end{array}$ & $\begin{array}{l}24.7 \\
(4.0)\end{array}$ & .83 & .87 & $\begin{array}{l}24.3 \\
(3.5)\end{array}$ & $\begin{array}{l}25.0 \\
(3.5)\end{array}$ & .90 & .93 & $\begin{array}{l}24.3 \\
(4.3)\end{array}$ & $\begin{array}{l}24.3 \\
(4.6)\end{array}$ \\
\hline & $\begin{array}{l}\text { Father-son } \\
\text { communication }\end{array}$ & $\begin{array}{l}24.3 \\
(3.6)\end{array}$ & $\begin{array}{c}25.0 \\
(4.0)\end{array}$ & .63 & .67 & $\begin{array}{l}24.2 \\
(3.6)\end{array}$ & $\begin{array}{l}25.0 \\
(3.8)\end{array}$ & .60 & .76 & $\begin{array}{l}24.3 \\
(3.6)\end{array}$ & $\begin{array}{l}25.0 \\
(4.1)\end{array}$ \\
\hline \multirow{2}{*}{$\begin{array}{l}\text { Sons' satisfaction } \\
\text { with paternal } \\
\text { engagement }\end{array}$} & $\begin{array}{l}\text { Father } \\
\text { involvement }\end{array}$ & $\begin{array}{l}17.7 \\
(2.9)\end{array}$ & $\begin{array}{l}18.1 \\
(2.6)\end{array}$ & .65 & .71 & $\begin{array}{l}17.4 \\
(2.8)\end{array}$ & $\begin{array}{l}17.7 \\
(2.8)\end{array}$ & .71 & .78 & $\begin{array}{c}18.1 \\
(3.0)\end{array}$ & $\begin{array}{l}18.5 \\
(2.3)\end{array}$ \\
\hline & $\begin{array}{l}\text { Father-son } \\
\text { communication }\end{array}$ & $\begin{array}{l}24.8 \\
(3.9)\end{array}$ & $\begin{array}{c}25.4 \\
(3.8)\end{array}$ & .62 & .62 & $\begin{array}{c}24.5 \\
(3.7)\end{array}$ & $\begin{array}{l}25.1 \\
(3.2)\end{array}$ & .71 & .75 & $\begin{array}{c}25.1 \\
(4.1)\end{array}$ & $\begin{array}{l}24.8 \\
(2.8)\end{array}$ \\
\hline $\begin{array}{l}\text { Sons' intentions } \\
\text { to avoid violence }\end{array}$ & $\begin{array}{l}\text { Intentions to } \\
\text { avoid violence }\end{array}$ & $\begin{array}{c}20.0 \\
(4.7)\end{array}$ & $\begin{array}{l}20.7 \\
(4.5)\end{array}$ & .70 & .76 & $\begin{array}{l}19.3 \\
(4.8)\end{array}$ & $\begin{array}{c}20.6 \\
(4.9)\end{array}$ & .74 & .73 & $\begin{array}{c}20.9 \\
(4.4)\end{array}$ & $\begin{array}{c}20.9 \\
(4.0)\end{array}$ \\
\hline
\end{tabular}


Parental involvement satisfaction. Five questions asked fathers and sons about their satisfaction with fathers' social support through parenting involvement with sons. These questions are satisfaction with: showing love and affection, protecting son in general, being a role model, disciplining son, and providing racial socialization for son. Fathers were also asked about their satisfaction with their regular financial support to their son and teaching their son about life. The response scale ranged from 1 (very dissatisfied) to 4 (very satisfied). Items were summed to create the scale scores, which ranged from 7 to 28 for fathers and 5 to 20 for sons. Higher scores indicate more satisfaction with fathers' parenting involvement. Cronbach's alphas for fathers were as follows: pretest $=.87$ and posttest $=.90$; and sons: pretest $=.72$ and posttest $=.74$.

Parenting skills satisfaction. Fathers were asked two questions assessing their satisfaction with their ability to supervise their sons and their overall satisfaction with their skills as a parent. The response scale ranged from 1 (very dissatisfied) to 4 (very satisfied). These two items were significantly correlated $(r=.45, p<.01)$; therefore, we created an index of parenting skills by summing the two items. The scale scores for this measure ranged from 2 to 8 . Higher scores indicate that fathers had greater satisfaction with their overall parenting skills. Cronbach's alphas for fathers were as follows: pretest $=.78$ and posttest $=.79$.

Intentions to avoid violence. The outcome measure for the parenting skills model is the Intentions to Use Non-Violent Strategies Scale (Bosworth, Espelage, \& Simon, 1999), an eight-item scale developed to assess children's plans to use nonviolent strategies in future anger-provoking situations. The stem for this scale is as follows: "Please tell me how often you would do any of the following things the next time you get really angry." Example responses include: "Try to talk it out with the person" and "Try not to be so angry." Sons' responses were measured on a 4-point scale ranging from 1 (never) to 4 (all the time). Scores range from 8 to 32, with higher scores indicating greater intentions to use nonviolent strategies or to avoid violence in the future. Cronbach's alphas for sons were as follows: pretest $=.73$ and posttest $=.75$.

\section{Fathers' Parenting Behaviors and Sons' Aggressive Behavior Measures}

Three scales were used to measure parenting behaviors reflecting risky behavior communication, communication about race-related socialization, and communication about sex. This construct represents fathers' actual communication with their son in three critical content areas with implications for preventing or reducing aggressive behaviors. Table 3 provides the descriptive statistics and Cronbach's alpha for each measure by intervention and comparison groups for fathers and sons. Following is the detailed description of the measures in the parenting behaviors model for the full sample, along with the measure of sons' aggressive behaviors.

Risky behavior communication. The Youth Assets Scale (HEART of OKC Website, 2002) assesses parent-child communication about multiple risky behaviors. We used this scale to evaluate whether fathers talked with sons about what they thought was right or wrong about six risky behaviors in the following areas: (a) violent behaviors, (b) having sex, (c) alcohol use, (d) smoking cigarettes, (e) marijuana use, and (f) use of other drugs. Fathers

Table 3

Pretest and Posttest Descriptive Statistics and Reliabilities for Parenting Behaviors Measures for Total Sample and by Group

\begin{tabular}{|c|c|c|c|c|c|c|c|c|c|c|c|}
\hline & & \multicolumn{2}{|c|}{ Total sample } & \multicolumn{4}{|c|}{ Intervention group } & \multicolumn{4}{|c|}{ Comparison group } \\
\hline & & $\begin{array}{l}\text { Pretest } \\
M(S D)\end{array}$ & $\begin{array}{l}\text { Posttest } \\
M(\mathrm{SD})\end{array}$ & $\begin{array}{l}\text { Pretest } \\
\text { alpha }\end{array}$ & $\begin{array}{c}\text { Posttest } \\
\text { alpha }\end{array}$ & $\begin{array}{l}\text { Pretest } \\
M(S D)\end{array}$ & $\begin{array}{l}\text { Posttest } \\
M(\mathrm{SD})\end{array}$ & $\begin{array}{c}\text { Pretest } \\
\text { alpha }\end{array}$ & $\begin{array}{c}\text { Posttest } \\
\text { alpha }\end{array}$ & $\begin{array}{l}\text { Pretest } \\
M(S D)\end{array}$ & $\begin{array}{l}\text { Posttest } \\
M(S D)\end{array}$ \\
\hline \multirow[t]{3}{*}{$\begin{array}{l}\text { Fathers' parenting } \\
\text { behaviors }\end{array}$} & $\begin{array}{l}\text { Risky behavior } \\
\text { communication }\end{array}$ & $\begin{array}{c}5.0 \\
(1.1)\end{array}$ & $\begin{array}{c}5.5 \\
(1.1)\end{array}$ & .90 & .84 & $\begin{array}{c}4.8 \\
(1.9)\end{array}$ & $\begin{array}{c}5.5 \\
(1.2)\end{array}$ & .86 & .78 & $\begin{array}{c}5.3 \\
(1.5)\end{array}$ & $\begin{array}{c}5.5 \\
(1.1)\end{array}$ \\
\hline & $\begin{array}{l}\text { Race-related } \\
\text { socialization }\end{array}$ & $\begin{array}{c}25.2 \\
(4.6)\end{array}$ & $\begin{array}{l}26.0 \\
(4.6)\end{array}$ & .72 & .69 & $\begin{array}{l}24.9 \\
(4.6)\end{array}$ & $\begin{array}{c}26.6 \\
(4.2)\end{array}$ & .76 & .80 & $\begin{array}{c}25.5 \\
(4.6)\end{array}$ & $\begin{array}{c}25.4 \\
(5.0)\end{array}$ \\
\hline & $\begin{array}{l}\text { Communication } \\
\text { about sex }\end{array}$ & $\begin{array}{l}10.0 \\
(4.3)\end{array}$ & $\begin{array}{c}11.0 \\
(4.2)\end{array}$ & .89 & .88 & $\begin{array}{c}9.8 \\
(4.4)\end{array}$ & $\begin{array}{l}11.0 \\
(4.3)\end{array}$ & .88 & .88 & $\begin{array}{l}10.2 \\
(4.2)\end{array}$ & $\begin{array}{l}11.1 \\
(4.1)\end{array}$ \\
\hline $\begin{array}{l}\text { Sons' aggressive } \\
\text { behaviors }\end{array}$ & & $\begin{array}{l}1.4 \\
(1.3)\end{array}$ & $\begin{array}{c}1.3 \\
(1.1)\end{array}$ & .67 & .55 & $\begin{array}{r}1.5^{*} \\
(1.3)\end{array}$ & $\begin{array}{c}1.4 \\
(1.2)\end{array}$ & .60 & .54 & $\begin{array}{c}1.2 \\
(1.2)\end{array}$ & $\begin{array}{c}1.0 \\
(1.1)\end{array}$ \\
\hline
\end{tabular}

${ }^{*} p=.006$ for pretest means. 
responded to the items using a yes-no response scale. The number of topics discussed was counted to create a measure of the extent of topics covered regarding risky behavior communication. Scores ranged from 0 to 6 , with higher numbers meaning more topics covered. Cronbach's alphas for fathers were as follows: pretest $=.89$ and posttest $=.81$.

Race-related socialization. The Racial Socialization Scale (Martin, 2000) is a measure of what fathers teach their sons about what it means to be Black. This nine-item measure was adapted from the National Survey of African Americans (Thornton, Chatters, Taylor, \& Allen, 1990). Examples of questions include: "I teach (or model to) my child that all individuals are equal in this society" and "I teach (or model to) my child that you should try to get along with all people." Items were scored on a response scale ranging from 1 (never) to 4 (all the time). The race-related socialization scale is the sum of the nine items. Higher scores indicate more racerelated socialization. Scores ranged from 9 to 36, with high scores meaning more engagement in race-related socialization. Cronbach's alphas for fathers were as follows: pretest $=.73$ and posttest $=.75$.

Communication about sex. Five items from Blake's Parent-Child Communication Scale's (Blake et al., 2001) subscale on frequency of parent-child communication about sex were used. Examples of items include: "How often have you talked with your son about": "How to get along with girls" and "Reasons to wait to have sex." Item responses ranged from 1 (never) to 4 (six or more times). The scale score is the sum of the four items, with scores ranging from 5 to 20. Higher scores indicate more frequent communication about sex. Cronbach's alphas for fathers were as follows: pretest $=.89$ and posttest $=.88$.

Sons' aggressive behaviors. Sons were asked to report the frequency of their aggressive behaviors "in the past 2 months" on a scale ranging from 0 (never) to 5 (five times or more). Sons reported how often they: (a) were in a physical fight, (b) hit or kicked people when angry, (c) broke things when angry, and (d) bullied other children. Because the frequencies of these behaviors were low, we dichotomized the response categories for each of the four aggressive behavior items to represent no (0) the behavior did not occur or yes (1) the behavior did occur. The scale score is the sum of the four items, ranging from 0 to 4 with higher scores indicating more aggressive behaviors. Cronbach's alphas for sons were as follows: pretest $=.65$ and posttest $=.56$.

\section{Data Analysis Strategy}

Bivariate associations and mean differences among variables were estimated using Pearson's correlations and independent samples $t$ tests, respectively. Structural equation models (SEMs) were used to test the effects of the intervention on outcomes of interest. SEMs were developed using a two-step modeling procedure (Kline, 2010). First, measurement models that included all variables (latent and measured) were tested to determine the adequacy of the indicators as measures of the latent factors. Second, full SEMs tested the hypotheses of interest. Error variances for corresponding pretest and posttest measures were correlated in all models tested. Pretest and posttest regression weights (factor loadings) were constrained to be equal for corresponding variables. The models were estimated using Amos 18.0, which computes maximum likelihood estimates in the presence of missing data (Allison, 2002; Arbuckle, 2009).

The adequacy of model fit was assessed by examining the chi-square statistic, the comparative fit index (CFI), and the root mean square error of approximation (RMSEA). Ideally, a nonsignificant chi-square statistic or a chi-square to degrees of freedom ratio of less than 2, a CFI above .90, and a RMSEA value of .06 or less are indicators of a model that it is a good fit to the data $(\mathrm{Hu} \&$ Bentler, 1999; Lei \& Lomax, 2005). As confirmation of mediation, we used a bootstrapping procedure in Amos to estimate and test the indirect effect of the intervention on sons' outcomes (McDonald \& Ho, 2002).

\section{Results}

The level of sons' aggressive behaviors for both the intervention and comparison groups was relatively low, whereas indicators of parent-child communication were relatively high, except for communication about sex (see Table 3). All pretest measures shown in Tables 2 and 3 for the intervention and comparison groups were tested for mean differences using the independent samples $t$ test. The only difference found was for aggressive behaviors, with sons in the intervention group having higher levels of aggressive behaviors than sons in the comparison group, $p=.006$. Bivariate correlations provided in Tables 4 and 5 show evidence of modest relations among variables tested within each SEM model. In general, pretest variables were associated with their paired posttest variables. 


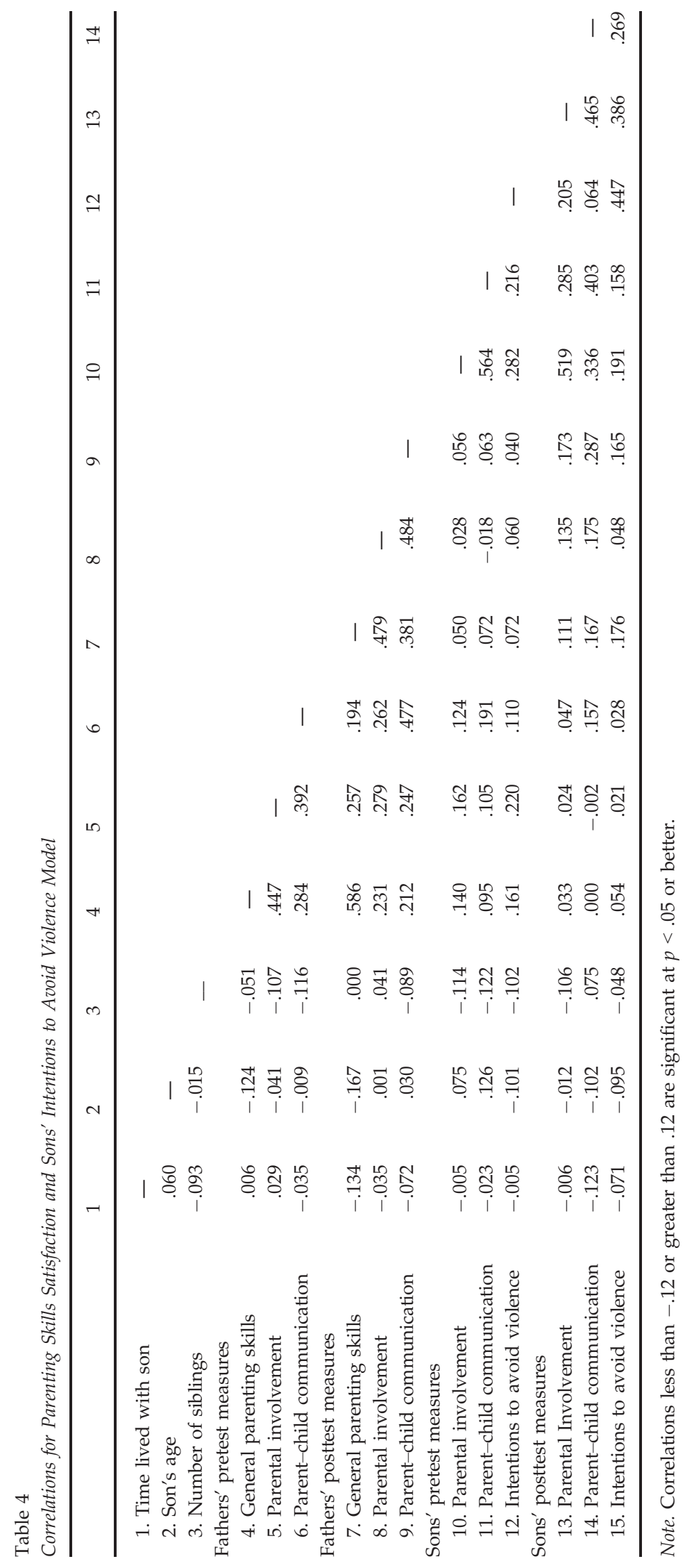




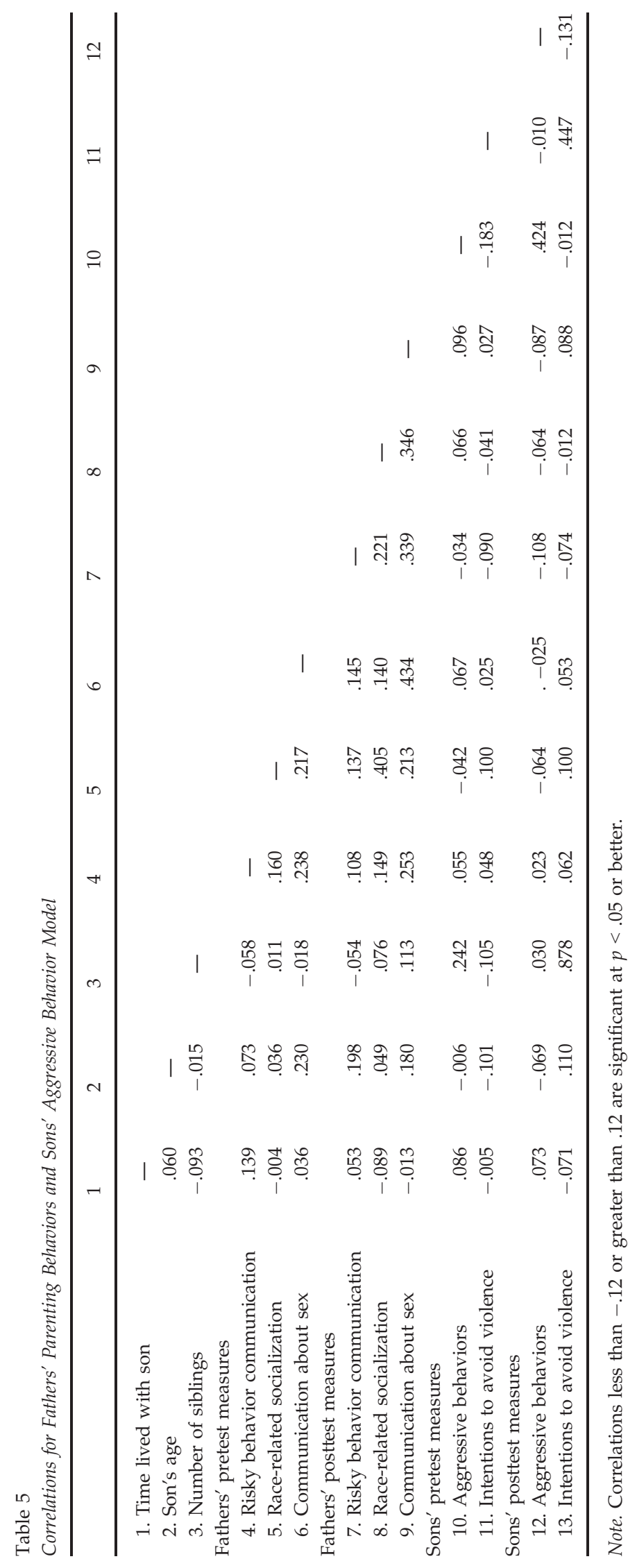


Variables used to measure latent constructs were moderately correlated for both fathers and sons.

\section{Parenting Skills Satisfaction and Sons' Intentions to Avoid Violence Model}

Fit statistics for the parenting skills satisfaction measurement model indicated an adequate fit of the model to the data, $\chi^{2}(65, n=287)=113.419$, $p=.000$, CFI $=.948$, RMSEA $=.051,90 \%$ CI $[0.035$, 0.066]. Although the chi-square test for the model was significant, the chi-square to degrees of freedom ratio (1.75) was less than 2, indicating a good fitting model. The standardized factor loadings for the parenting skills satisfaction scales ranged from .54 to .75 for fathers and paternal engagement ranged from .67 to .75 for sons. The fit of the full SEM (see Figure 1) was good, $\chi^{2}(81, n=287)=135.70, p<.001, \chi^{2} /$ $d f=1.68$, CFI $=.941$, RMSEA $=.050,90 \%$ CI $[0.036$, 0.064]. The path from group to fathers' parenting skills satisfaction was positive and significant, indicating the intervention enhanced fathers' parenting skills satisfaction. The path from fathers' parenting skills satisfaction to sons' satisfaction with paternal engagement also was positive and significant, suggesting that improving fathers' parenting skills satis- faction was associated with increases in sons' satisfaction with paternal engagement. The path from sons' satisfaction with paternal engagement to sons' intentions to avoid violence was also positive and significant.

As confirmation of mediation we used the bootstrapping procedure in Amos to estimate and test the indirect effect of the intervention on sons' satisfaction with paternal engagement, and the indirect effect of fathers' parenting skills satisfaction on sons' intentions to avoid violence through sons' satisfaction with paternal engagement. The regression coefficient for group to fathers' parenting skills satisfaction to sons' satisfaction with paternal engagement path was $0.086,90 \%$ CI [0.042, 0.333]. The regression coefficient for the indirect path to sons' intentions to avoid violence was $-0.362,90 \%$ CI $[-0.775,-0.010]$. These results support our hypotheses that the intervention would have an indirect effect on sons' satisfaction with paternal engagement through improvements in fathers' parenting skills satisfaction, and that the intervention would have an indirect effect on sons' intention to avoid violence through improvements in fathers' parenting skills satisfaction and sons' satisfaction with paternal engagement.

Pretest

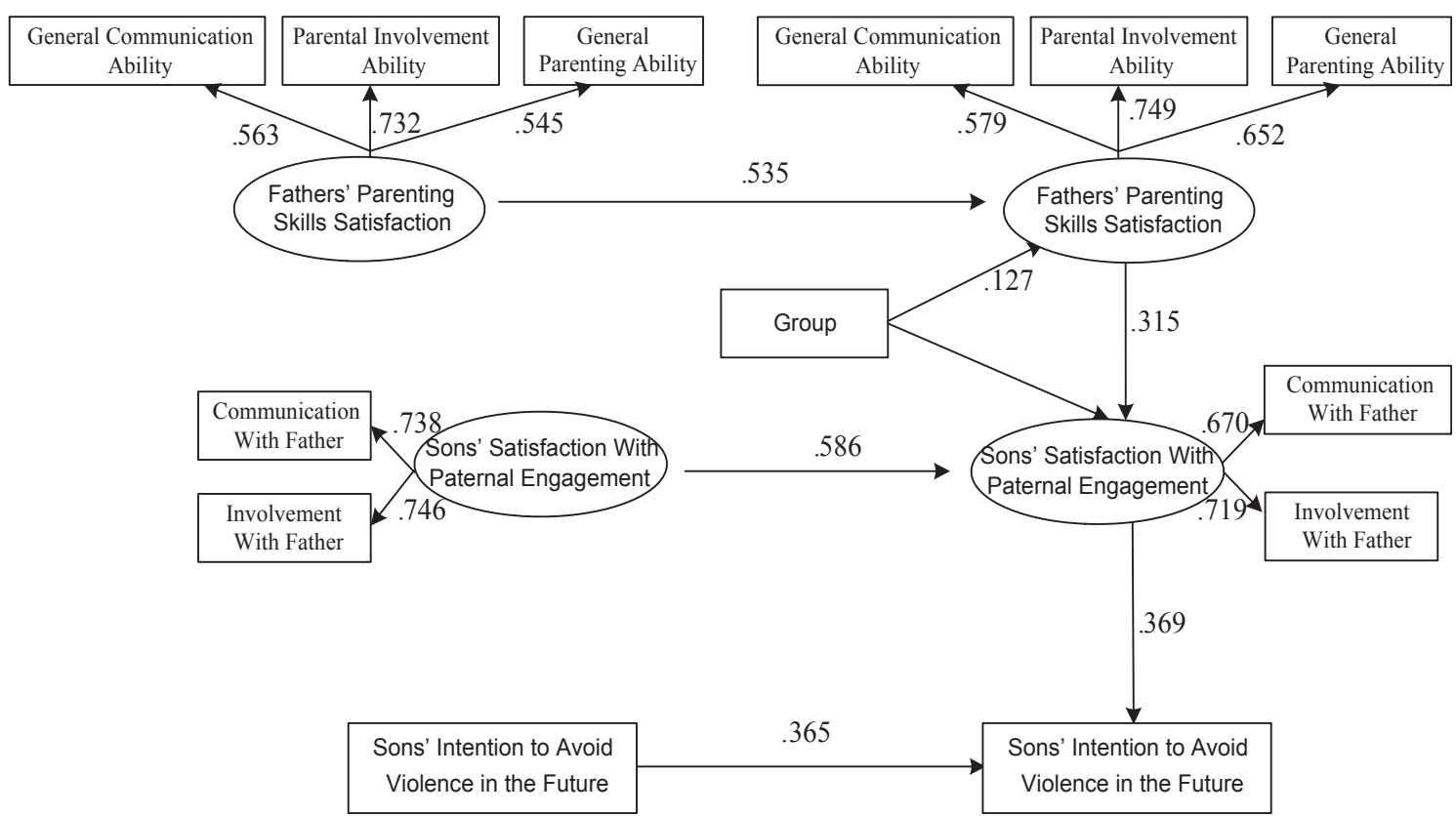

Figure 1. Parenting skills satisfaction and sons' intentions to avoid violence model. Numbers are standardized regression coefficients. Significant regression coefficients have been shown only. Chi-square $=135.70, d f=81, p=.001$, root mean square error of approximation $=.050,90 \%$ CI $[0.036,0.064]$, comparative fit index $=.941$, minimum value of the discrepancy function $/ d f=1.68$. The group variable was correlated with all pretest factors in the structural equation model. 


\section{Fathers' Parenting Behaviors for Risk Communication and Sons' Aggressive Behaviors Model}

Fit statistics for the fathers' parenting behaviors for risk communication measurement model were good, $\chi^{2}(39, n=287)=53.779, p=.06, \chi^{2} / d f=1.38$, CFI $=.963$, RMSEA $=.036,90 \%$ CI $[0.000,0.058]$. Standardized factor loadings for the parenting behaviors scales ranged from .30 to .72. The full SEM (see Figure 2) also was a good fit to the data, $\chi^{2}(53, \quad n=287)=67.08, \quad p=.09, \quad \chi^{2} / d f=1.27$, $\mathrm{CFI}=.965$, RMSEA $=.030,90 \%$ CI $[0.000,0.051]$. The path from group to fathers' parenting behaviors was positive, suggesting improvements in parenting behaviors for risk communication for fathers following the intervention. The path from fathers' parenting behaviors to sons' aggressive behaviors was significant and negative. There was also a significant direct positive path from group to sons' aggressive behavior. The path from sons' aggressive behaviors to their intention to avoid violence in the future was significant and negative.

The indirect effect of the intervention on sons' aggressive behaviors through fathers' parenting behaviors for risk communication was confirmed with the bootstrapping procedure. The regression coefficient was $-.049,90 \%$ CI $[-0.174,0.001]$. The indirect effect of the same path continuing to sons' intention to avoid violence was $-.169,90 \% \mathrm{CI}$ $[-0.398,0.041]$. These results support our hypotheses that the intervention had an indirect effect on sons' intentions to avoid violence in the future through (a) improvements in fathers' parenting behaviors for risk communication and (b) decreases in sons' aggressive behaviors.

\section{Discussion}

This study contributes to an emerging literature that shows that some nonresident African American fathers are involved and can have a protective effect on their children's well-being. Focusing on the protective effects of involved nonresident African American fathers is different from most studies that have examined nonresident African Americans fathers as a risk factor for youth violence. Based on our findings, most of the sons' births were nonmarital; however, more than three fourths of the nonresident fathers had lived with their sons during early childhood. In addition, most fathers had a legal child support agreement at the time of the study. Our findings show that these fathers continued to be involved with their sons when they were 8-12 years old. Other

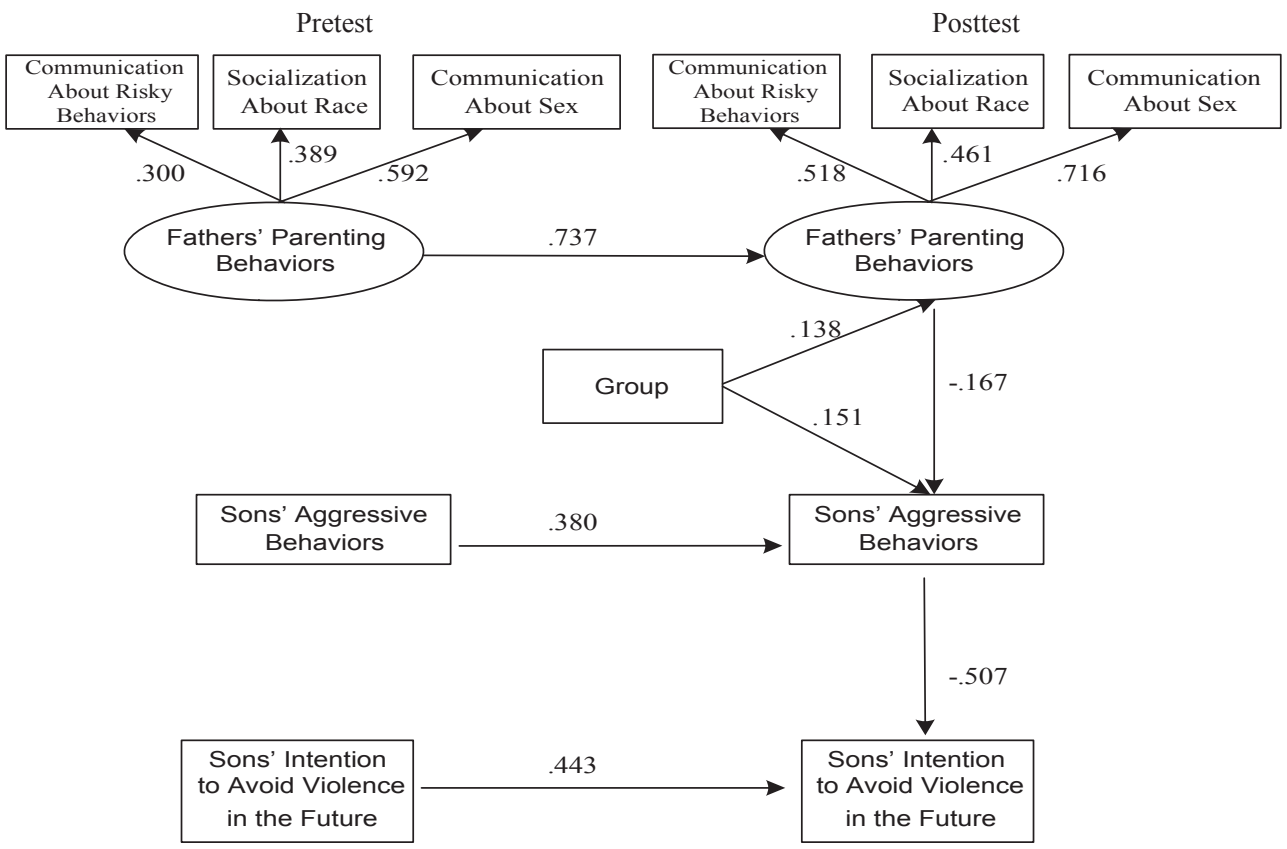

Figure 2. Fathers' parenting behaviors and sons' aggression model. Numbers are standardized regression coefficients. Only significant regression coefficients have been shown. Chi-square $=67.08, d f=53, p=.093$, root mean square error of approximation $=.03,90 \% \mathrm{CI}$ $[0.000,0.051]$, comparative fit index $=.965$, minimum value of the discrepancy function $/ d f=1.27$. The group variable was correlated with all pretest factors in the structural equation model. 
studies also support the involvement of nonresident African American fathers with their children (Bryant \& Zimmerman, 2003; Coley \& Medeiros, 2007; King et al., 2004), and Edin et al. (2009) showed that such involvement is often independent of romantic relationships with mothers.

Although the families in our study were facing challenges due to economic hardship and community violence, our findings suggest that family strengths exists that support normative development at late childhood and preadolescence. In general, we found good communication between these nonresident African American fathers and sons and relatively low levels of aggressive behaviors for boys in both the intervention and comparison groups. As a preventive intervention, the Fathers and Sons Program is designed to enhance the parenting of nonresident African American fathers when their sons were in the third to sixth grades. This is consistent with findings from the the MVVP (2009), which indicated that early sixth grade was a critical period for parental attitude influences on physical aggression and the ideal time to provide family supports for prevention. It also fits the early intervention matrix of Rosenberg et al. (2005).

Although the effects are modest, findings confirm our hypotheses regarding the benefits of the Fathers and Sons Program for improving fathers' parenting and child outcomes within nonresident African American father-son families. Specifically, when parenting skills satisfaction is improved among fathers, their sons benefit by being satisfied with how engaged their fathers are in a number of parenting tasks. Sons' paternal engagement satisfaction is then associated with their intentions to avoid violence in the future.

Our findings support the call by other researchers (King et al., 2004; Thomas, Krampe, \& Newton, 2008) to move beyond an examination of mere contact in research with nonresident fathers to better understand what may motivate nonresident fathers to be involved in the lives of their children and to understand what they do. We found that parenting skills satisfaction among fathers is linked to sons' satisfaction with paternal engagement, which may be especially rewarding for fathers. Satisfaction with their ability to communicate with sons about sensitive topics and accomplishing supportive parenting tasks may strengthen the father role identity of nonresident fathers, perhaps contributing to stronger bonds between fathers and sons. These fathers may convey their parenting skills satisfaction in ways that sons recognize and process in prosocial ways.
We did confirmed the indirect effect of the Fathers and Sons Program on sons' violence avoidance intentions through improvements in fathers' parenting skills satisfaction and sons' satisfaction with paternal engagement. Future interventions with involved nonresident African American fathers should incorporate specific parent skills training into areas such as general father-son communication, race-related socialization, discipline, role modeling, and how to show love and affection. This would provide concrete areas in which parenting assessments can be made with regard to parenting skills satisfaction for fathers. Paternal engagement assessments for sons would also be easier, perhaps contributing to their sense of belonging, self-esteem, and self-regulation. Past research identified parental rejection and neglect as family precursors in the developmental course of youth violence (Dahlberg \& Potter, 2001). Not being rejected by nonresident fathers is an important violence prevention strategy to build upon for African American boys with nonresident fathers. We suggest that enhancing the parenting skills satisfaction of nonresident African American fathers may be a promising motivational factor to explore in future intervention research.

We also found that improving fathers' parenting behaviors focused on the cumulative effects of communicating about risky behaviors, race, and sex is associated with a reduction in aggressive behaviors in their sons. A reduction in sons' aggressive behaviors is then associated with an increase in sons' intentions to avoid violence in the future. Based on the TRA, intentions to avoid violence are essential to maintain over time if preventing youth violence is to be achieved. Our results show promise for interrupting the developmental course of violence and that nonresident African American fathers may play a role in this process. The parenting behaviors addressed in our study are the same as those included in the SAAF (Brody et al., 2004), providing additional evidence of the need for general and culturally specific parenting behaviors to reduce aggression in African American youth.

Effective parent-child communication about racial issues and risky behaviors, including violence and sex, are components of the Fathers and Sons Program that were specifically tailored for nonresident African American fathers and sons because of the more limited contact these family members have with each other compared to resident families (Caldwell et al., 2011). Communicating prosocial expectations and values about risky behaviors and providing strategies for handling challenging situations that incorporate the realities of race and 
violence exposures into their lives were reinforced as critical parenting behaviors for African American fathers. Opportunities to practice communication skills in these areas in the Fathers and Sons intervention were essential. Participating in the intervention together provided the necessary time for fathers to communicate sensitive messages about race, violence, and sex to their sons, which is a necessary strategy to assist sons in managing their feelings about aggression (Brody et al., 2004).

An especially noteworthy finding in this study is that the intervention appears to reduce aggressive behaviors in sons indirectly through its effects on improving fathers' risk communication behaviors. This finding is consistent with our theoretical conceptualization for the Fathers and Sons Program that did not assume a direct association of intervention effects on sons' aggressive behaviors. The Fathers and Sons Program was designed as a family-centered intervention focused on enhancing the parenting of nonresident African American fathers, shifting attention from the influence of the intervention on the boys independently to the expanded family environment beyond household walls.

The shift to the expanded family environment is consistent with social ecological models that consider multiple levels of influence on the development of youth violence (Dahlberg \& Potter, 2001; Rosenberg et al., 2005). Our goal was to mobilize and prepare involved nonresident African American fathers to improve their parenting abilities to better guide their sons as they navigate the challenges of adolescence as African American male adolescents growing up in risky neighborhoods. Additional research is needed to determine if our findings will vary by sons' age or the length of time they lived with fathers before becoming nonresident. These concepts represent distinct developmental periods (i.e., 8-10, 11-12) and living experiences (i.e., $<5$ years, $5+$ years) that may moderate the effects of the intervention because of the implications for differential bonding experiences between father and sons.

Most family-centered youth violence interventions are conducted with mothers and children. Our findings have implications for those interventions, as well. Previous studies have shown that conflict between fathers and mothers is not uncommon within nonresident families (Anderson, Kohler, \& Letiecq, 2005), yet it is the quality of the coparenting relationship that influences father involvement (Carlson, Mclanahan, \& Brooks-Gunn, 2008). Based on our findings, future family-centered youth violence interventions with mothers should include helping mothers learn how to support fathers' efforts to become better parents. Paternal parenting skills satisfaction may be a good place to begin. In addition, agreement between mother and father regarding family values and expectations for sons' risky behaviors would reduce their child's conflicting subjective norms from each parent. It is not clear from our research whose norms the son would be most motivated to comply with if there is a conflict. This remains an empirical question for future research.

Interestingly, when the direct effect of the intervention was examined, there is a larger reduction in aggressive behaviors among comparison group sons. Although there is a possibility that this finding is due to chance, there are other plausible explanations as well. Violence was the second most frequently discussed topic during our intervention; therefore, continued reporting of aggressive behaviors for intervention sons at posttest may be related to memory processing and storage of themes about aggressive behaviors. Because memory is stored in an associative network, discussions about aggression may activate memory related to aggressive behavior (Lochman, 2004), which may result in hypervigilant reporting of behaviors at posttest among intervention group sons.

We must also consider an iatrogenic effect of the intervention as an explanation. That is, because this is a family-centered intervention, if fathers do not improve their parenting behaviors, then perhaps exposure to discussions about aggression may increase aggressive behaviors in their sons. It is unlikely that the intervention has had a harmful effect because the pretest-posttest means suggest a decrease rather than an increase has occurred for sons in the intervention group as well. Comparison group sons show a larger decrease, accounting for the observed difference between groups at posttest. Brody et al. (2004) suggested that it is necessary to measure outcomes long after the intervention has ended to effectively test its effects to allow time for "any transitory immediate effects to dissipate" (p. 912). This was the case for the MVPP (2009) intervention study where physical aggression occurred gradually over 2 years. Further research will be necessary to examine long-term results to fully determine our intervention effects. In general, the short-term results support the effects of the Fathers and Sons Program on sons' outcomes through enhancements of fathers' parenting as conceptualized.

Although encouraging, findings from this study must be viewed within the context of several study 
limitations. Families recruited for this study were not randomly assigned to the intervention and comparison groups; therefore, a self-selection bias may exist resulting in more motivated fathers and sons participating in the intervention group. Comparison group families did not receive an alternative program; however, they completed the pretest and posttest questionnaires in about the same time frame as intervention group families and received the same compensation for completing evaluation questionnaires. There was differential attrition between the intervention and comparison group families. This was partially due to logistical reasons rather than participant refusals. Nevertheless, the final sample for this study is not representative of nonresident African American father-son families and the sample size is relatively small.

This study is also limited because it does not account for mother influences on child outcomes, even though mothers are the custodial parent. Consequently, father effects cannot be assessed net of mother effects or in combination with mother effects. Thus, a more comprehensive assessment of family influences on child outcomes could not be determined. The correlations between fathers' and sons' reports for parenting behaviors (e.g., communication, involvement) were low. This does not negate the validity of these reports because parenting research often shows low correlations in studies of parent-child perceptions of parenting practices (Pasch, Stigler, Perry, \& Komro, 2010; Taber, 2010). In addition, the reliability for aggressive behavior, a key outcome measure, is lower than desired. The scale included only four dichotomous items. Ideally, future studies should use a stronger, more psychometrically sound, measure to confirm study results. Finally, the long-term intervention effects have not been assessed, which will be necessary to determine if observed changes can be sustained over time as the sons age into critical adolescent developmental stages where youth risky behaviors are expected to increase and peer influences will be stronger.

This study is unique in its attempt to identify family strengths for African American fathers and sons who do not live together as a critical area for exploration in youth violence prevention initiatives. Findings from this study contribute to an emerging literature that highlights the influential role involved nonresident African American fathers can play in comprehensive violence prevention efforts that consider the developmental needs of boys, while recognizing that many fathers require assistance in fulfilling their fathering responsibilities. As previous studies have shown, African American nonresident fathers represent an underutilized resource that can be mobilized for the sake of their children. Our findings suggest that the Fathers and Sons Program is promising for enhancing the parenting skills satisfaction and parenting behaviors for risk communication among nonresident African American fathers. Importantly, these parental enhancements are associated with their sons' intentions to avoid violence and a reduction in sons' aggressive behaviors.

The primary implication of this research is that strengthening nonresident African American fathers' parenting skills satisfaction and parenting behaviors may add sources of support so that African American boys exposed to community violence have more opportunities to succeed and thrive as they learn to manage their own aggression. The families in our study are those who may not be the beneficiaries of institutional or legal programs that are typically designed for the most at-risk youth based on the sons' current levels of aggressive behaviors. Programs like the Fathers and Sons Program are especially relevant for implementation in community settings where parents determine the need for family participation. These families may be seeking additional support for lower risk youth living in high-risk environments. Policy makers and practitioners concerned with preventing youth violence should consider ways to assist involved nonresident African American fathers stay connected to their children, especially their sons, and support them in effectively performing their fathering responsibilities as an innovative and potentially sustainable approach to violence prevention.

\section{References}

Ajzen, I., \& Fishbein, M. (1980). Understanding attitudes and predicting social behavior. Englewood Cliffs, NJ: Prentice Hall.

Allison, P. D. (2002). Missing data. Sage University Papers Series on Quantitative Applications in the Social Sciences, 07-136. Thousand Oaks, CA: Sage.

Amato, P. R., Meyers, C. E., \& Emery, R. E. (2009). Changes in nonresident father-child contact from 1976-2002. Family Relations, 58, 41-53.

Anderson, E. A., Kohler, J. K., \& Letiecq, B. L. (2005). Predictors of depression among low-income, nonresidential fathers. Journal of Family Issues, 26, 547-567.

Arbuckle, A. J. (2009). Amos 18 user's guide. Crawfordville, FL: Amos Development.

Barnes, H. L., \& Olson, D. H. (1985). Parent-adolescent communication and the circumplex model. Child Development, 56, 438-447. 
Blake, S. M., Simkin, L., Ledsky, R., Perkins, C., \& Calabrese, J. M. (2001). Effects of parent-child communications intervention on young adolescents' risk for early onset of sexual intercourse. Family Planning Perspectives, 33, 52-61.

Bosworth, K., Espelage, D. L., \& Simon, T. R. (1999). Factors associated with bullying behavior in middle school students. Journal of Early Adolescence, 23, 341-362.

Brody, G., Murry, V., Gerrard, M., Gibbons, F. X., Molgaard, V., McNair, L., et al. (2004). The strong African American families program: Translating research into prevention programming. Child Development, 75, 900917.

Bronfenbrenner, U. (1977). Toward an experimental ecology of human development. American Psychologist, 32, 513-531.

Bryant, A. L., \& Zimmerman, M. A. (2003). Role models and psychosocial outcomes among African American adolescents. Journal of Adolescent Research, 18, 36-67.

Caldwell, C. H., De Loney, E. H., Mincy, R., Klempin, S., Brooks, C. L., \& Rafferty, J. (2011). Strengthening bonds between nonresident African American fathers and sons as a way to reduce or prevent youth risky behaviors. In C. Haen (Ed.), Creative approaches for engaging boys in treatment. Routledge book series on counseling and psychotherapy with boys and men (pp. 265-291). New York: Routledge.

Caldwell, C. H., Rafferty, J., Reischl, T., De Loney, E. H., \& Brooks, C. L. (2010). Enhancing parenting skills among nonresident African American fathers as a strategy for preventing youth risky behaviors. American Journal of Community Psychology, 45, 17-35.

Caldwell, C. H., Wright, J. C., Zimmerman, M. A., Walsemann, K. M., Williams, D., \& Isichei, P. A. (2004). Enhancing adolescent health behaviors through strengthening non-resident father-son relationships: A model for intervention with African-American families. Health Education Research, 19, 644-656.

Carlson, M. J. (2006). Family structure, father involvement, and adolescent behavioral outcomes. Journal of Marriage and Family, 68, 137-154.

Carlson, M. J., Mclanahan, S. S., \& Brooks-Gunn, J. (2008). Co-parenting and nonresident fathers: Involvement with young children after a nonmarital birth. Demography, 45, 461-488.

Coley, R. L., \& Medeiros, B. L. (2007). Reciprocal longitudinal relations between nonresident father involvement and adolescent delinquency. Child Development, 78, 132147.

Copeland-Linder, N., Lambert, S. F., Chen, Y., \& Ialongo, N. S. (2011). Contextual stress and health risk behaviors among African American adolescents. Journal of Youth and Adolescence, 40, 158-173.

Dahlberg, L. L., \& Potter, L. B. (2001). Youth violence: Developmental pathways and prevention challenges. American Journal of Preventive Medicine, 20, 3-14.

Dilorio, C., McCarty, F., \& Denzmore, P. (2006). An exploration of social cognitive theory mediators of father-son communication about sex. Journal of Pediatric Psychology, 31, 917-927.

Edin, K., Tach, L., \& Mincy, R. B. (2009). Claiming fatherhood: Race and the dynamics of paternal involvement among unmarried men. Annals of the American Academy of Political and Social Science, 621, 149-177.

Farrell, A. D., Henry, D. B., Mays, S. A., \& Schoeny, M. E. (2011). Parents as moderators of the impact of school norm and peer influences on aggression in middle school students. Child Development, 82, 146-161.

Fisher, C. B., Wallace, S. A., \& Fenton, R. E. (2000). Discrimination distress during adolescence. Journal of Youth and Adolescence, 29, 679-695.

Garcia Coll, C., Lamberty, G., Jenkins, R., McAdoo, H. P., Crnic, K., Wasik, B. H., et al. (1996). An integrative model for the study of developmental competencies in minority children. Child Development, 67, 1891-1914.

Griffin, K. W., Botvin, G. L., Scheier, L. M., Diaz, T., \& Miller, N. L. (2000). Parenting practices as predictors of substance use, delinquency, and aggression among urban minority youth: Moderating effects of family structure and gender. Psychology of Addictive Behaviors, 14, 174-184.

Gutman, L. M., McLoyd, V. C., \& Tokoyama, T. (2005). Financial strain, neighborhood stress, parenting behaviors and adolescent adjustment in urban African American families. Journal of Research on Adolescence, 15, 425-449.

Harris-Britt, A., Valrie, C. R., Kurtz-Costes, B., \& Rowley, S. J. (2007). Perceived racial discrimination and selfesteem in African American youth: Racial socialization as a protective factor. Journal of Research on Adolescence, 17, 669-682.

HEART of OKC Website. (2002). Reducing teen pregnancy in Oklahoma: Focusing on older teens (18-19 years old). The Healthy, Empowered and Responsible Teens of Oklahoma City (HEART OKC). Retrieved January 2002, from http:/ /www.health.state. ok.us/program/hpromo/medj/oteens.html

Hu, L., \& Bentler, P. M. (1999). Cutoff criteria for fit indexes in covariance structure analysis: Conventional criteria versus new alternatives. Structural Equation Modeling, 6, 1-55.

Hughes, D., Rodriguez, J., Smith, E., Johnson, D., Stevenson, H., \& Spicer, P. (2006). Parental ethnic racial socialization practices: A review of research and directions for future study. Developmental Psychology, 42, 747-770.

Hunter, A. G., \& Sellers, S. (1998). Feminist attitudes among African American women and men. Gender $\mathcal{E}$ Society, 12, 81-99.

Isacco, A., Garfield, C. F., \& Rogers, T. E. (2010). Correlates of coparental support among married and nonmarried fathers. Psychology of Men and Masculinity, 11, 262-278.

Israel, B. A., Eng, E., Schulz, A. J., \& Parker, E. A. (Eds.). (2005). Methods in community-based participatory research for health. San Francisco: Jossey-Bass. 
Israel, B. A., \& Rounds, K. A. (1987). Social networks and social support: A synthesis for health educators. Advances on Health Education and Promotion, 2, 311-351.

Kim, S., \& Brody, G. H. (2005). Longitudinal pathways to psychological adjustment among Black youth living in single-parent households. Journal of Family Psychology, 19, 305-313.

King, V., Harris, K. M., \& Heard, H. E. (2004). Racial and ethnic diversity in nonresident father involvement. Journal of Marriage and Family, 66, 1-21.

King, V., \& Sobolewski, J. M. (2006). Nonresident fathers' contributions to adolescent well-being. Journal of Marriage and Family, 68, 537-557.

Kline, R. B. (2010). Principles and practice of structural equation modeling (3rd ed.). New York: Guilford Press.

Leavell, A. S., Tamis-LeMonda, C. S., Ruble, D. N., Zosuls, K. M., \& Cabrera, N. J. (2012). African American, White and Latino fathers' activities with their sons and daughters in early childhood. Sex Roles, 66, 53-65.

Lei, M., \& Lomax, R. G. (2005). The effect of varying degrees of nonormality in structural equation modeling. Structural Equation Modeling, 12, 1-27.

Li, X., Feligelman, S., \& Stanton, B. (2000). Perceived parental monitoring and health risky behaviors among urban low-income African American children and adolescents. Journal of Adolescent Health, 27, 43-48.

Lochman, J. E. (2004). Contextual factors in risk and prevention research. Merrill Palmer Quarterly, 50, 311-325.

Mackey, W. C., \& Immerman, R. S. (2004). The presence of the social father in inhibiting young men's violence. Mankind Quarterly, 44, 339-366.

Marsiglio, W., Amato, P., Day, R. D., \& Lamb, M. E. (2000). Scholarship on fatherhood in the 1990s and beyond. Journal of Marriage and Family, 62, 1173-1191.

Martin, P. (2000). The African American church and African American parents: Examining relationships between racial socialization practices and racial identity attitudes. Unpublished dissertation, Michigan State University, East Lansing.

McDonald, R. P., \& Ho, M.-H. R. (2002). Principles and practice in reporting structural equation analyses. Psychological Methods, 7, 64-82.

McLoyd, V. C. (1998). Socioeconomic disadvantage and child development. American Psychologist, 53, 185-204.

Multisite Violence Prevention Project (2009). The ecological effects of universal and selective violence prevention programs for middle school students: A randomized trial. Journal of Consulting and Clinical Psychology, 77, 526-542.

Murphy, D., Marelich, W., Herbeck, D., \& Payne, D. (2009). Family routines and parental monitoring as protective factors among early and middle adolescents affected by maternal HIV/AIDS. Child Development, 80, 1676-1691.

Murry, V., Berkel, C., Brody, G., Miller, S., \& Chen, Y. (2009). Linking parental socialization to interpersonal protective processes, academic self-presentation, and expectations among rural African American youth. Cultural Diversity-Ethnic Minority Psychology, 15, 1-10.
National Fatherhood Initiative. (2011). Father facts, (6th ed.). Germantown, MD: Fatherhood Resource Center.

Pasch, K. E., Stigler, M. H., Perry, C. L., \& Komro, K. A. (2010). Parents' and children's self report of parenting factors: How much do they agree and which is more strongly associated with early adolescent alcohol use? Health Education Journal, 69, 31-42.

Roberts, M. E., Gibbons, F. X., Gerrard, M., Weng, C.- Y., Murry, V. M., Simons, L. G., et al. (2012). From racial discrimination to risky sex: Prospective relations involving peers and parents. Developmental Psychology, 48, 89-102.

Rosenberg, M., Lyndee, M., \& Knox, L. M. (2005). The matrix comes to youth violence prevention: A strengthsbased, ecologic, and developmental framework. American Journal of Preventive Medicine, 29, 185-190.

Seaton, E. K., Caldwell, C. H., Sellers, R. M., \& Jackson, J. S. (2008). The prevalence of perceived discrimination among African American and Caribbean Black youth. Developmental Psychology, 44, 1288-1297.

Smith, E. P., Gorman-Smith, D., Quinn, W. H., Rabiner, D. L., Tolan, P. H., Winn, D. M., et al. (2004). Communitybased multiple family groups to prevent and reduce violent and aggressive behavior: The GREAT families program. American Journal of Preventive Medicine, 26, 39-47.

Spencer, M. B. (2006). Revisiting the 1990 special issue on minority children: An editorial perspective 15 years later. Child Development, 77, 1149-1154.

Taber, S. M. (2010). The veridicality of children's reports of parenting: A review of factors contributing to parent-child discrepancies. Clinical Psychology Review, 30, 999-1010.

Thomas, P. A., Krampe, E. M., \& Newton, R. R. (2008). Father presence, family structure, and feelings of closeness to the father among adult African American children. Journal of Black Studies, 38, 529-546.

Thornton, M., Chatters, L., Taylor, R., \& Allen, W. (1990). Sociodemographic and environmental correlates of racial socialization by Black parents. Child Development, 61, 401-409.

Thornton, T. N., Craft, C. A., Dahlberg, L. L., Lynch, B. S., \& Baer, K. (2002). Best practices of youth violence prevention: A sourcebook for community action. Atlanta, GA: Division of Violence Prevention, National Center for Injury Prevention and Control, Centers for Disease Control and Prevention.

U.S. Department of Health and Human Services. (2001). Youth violence: A report of the surgeon general. Washington, DC: U.S. Department of Justice.

U.S. National Center for Health Statistics. (2010). National Vital Statistics Report (NVSR): Final Data for 2008, Vol. 59, No. 1. Hyattsville, MD: National Center for Health Statistics.

Wills, T., Gibbons, F., Gerrard, M., Murry, V., \& Brody, G. H. (2003). Family communication and religiosity related to substance use and sexual behavior in early adolescence: A test for pathways through self-control and prototype perceptions. Psychology of Addictive Behaviors, 17, 312-323. 